\title{
Realising the Threshold of Employability in Higher Education
}

\author{
Chris Procter and Vicki Harvey
}

\begin{abstract}
A substantial body of work has tested and developed 'Threshold Concepts'. A Threshold Concept may be considered "akin to a portal, opening up a new and previously inaccessible way of thinking about something ... it represents a transformed way of understanding, or interpreting, or viewing ... without which the learner cannot progress" (Meyer and Land in Threshold concepts and troublesome knowledge 1-Linkages to ways of thinking and practising in improving student learning-Ten years on. OCSLD, Oxford, 2003). Little research however exists on the relevance of the concept to employability. Employability is fundamental to Higher Education, yet its role in the curriculum is unclear and contested. Our practice suggests that developing knowledge about employability is a threshold which, when reached, empowers and gives confidence to the student. To achieve this means embedding this knowledge in the curriculum. The paper discusses the delivery of a large module with this aim, explaining how the design of assessment was fundamental in guiding students to a transformed way of understanding employability.
\end{abstract}

Keywords Employability - Threshold concepts · Competencies · Professional

development

\section{$1 \quad$ Introduction}

Since the mid 1960s there has been significant change which has paved the way for the development of the current employability agenda in Higher Education (HE) in the United Kingdom (UK). The Robbins report of 1963 (Barr 2014) heralded the creation of many new Higher Education Institutions (HEIs) to ensure that all who were qualified and wished to enter should be able do so (Barr 2014). Figures from the Higher Education Statistics Agency (HESA 2017a) indicate that there have since been consistent increases in student enrolments. With the number of first year, first degree student enrolments standing at 542,575 for $2015 / 16$, this shows a $3 \%$ increase year on year since 2006/07.

The UK has the second highest graduation rate in the OECD, with around $47 \%$ of school leavers entering HE, but such growth is not replicated in the graduate 
labour market (The Guardian 2016; CIPD 2015). Government figures suggest that $31 \%$ of all graduates are not doing graduate — or high-skilled-jobs (BIS 2016a). Employers report (Archer and Davison 2008; Woods and Dennis 2009) that graduates are not work ready and do not have the requisite competencies. Despite a substantial number of under-employed graduates, employers continuously report a skills shortage (CIPD 2014; CBI 2015), and the role of HE in facilitating this gap is continually called into question (Cranmer 2006). Successive UK governments have responded by steadily increasing the pressure on HEIs to demonstrate the employability of their graduates. When considering Computing graduates specifically, The Tech Partnership report (Matthews 2017) emphasises the gap between student and employer expectations and the need for Universities to develop employability skills. The review conducted by the Higher Education Funding Council for England (HEFCE) led by Nigel Shadbolt (HEFCE 2017) recommended a much greater emphasis on employability and proposed integrating 'work ready' skills as an accredited part of the curriculum.

Following a brief explanation of the evolution of policy, this paper discusses how employability is defined as a set of competencies by employers. It then addresses how best HEIs can help students to demonstrate their employability arguing that this is best achieved by initiatives embedded within the curriculum. We explain the relevance of theory concerning Threshold Concepts and how assessment can be used as the lever to enable students to realise what we term the threshold of employability. The paper explains the design and implementation of a large multidisciplinary module undertaken by undergraduates. Whilst they were largely on business related programmes(includingIT)theapproachisequallyvalidforcomputingstudents. Student reflection and feedback is used to demonstrate the relevance of our approach. Conclusions are drawn concerning the value of embedding employability in the curriculum to help students conquer their 'Monsters of doubt' (Hawkins and Edwards 2013).

\section{Development of Government Policy on Employability}

For over two decades successive governments have sought to intervene to ensure that HEIs addressed the gap between graduate capability and the requirements of the labour market (Artess et al. 2017). The Dearing report (NCIHE 1997) provided a major impetus for UK HEIs to become engaged in employability skills development. There has been a continued policy emphasis on the strong relationship between HE and economic prosperity, and consequent need for the production of 'employable' graduates (BIS 2016b).

Since the turn of the century policy measures have sought to inculcate employability into programmes of study by the use of national metrics. The Destination

LeaversfromHigherEducation(DLHE)survey, whichcommencedin2003, hasbeen 
conductedwithallformerundergraduatestudentssixmonthsaftertheirgraduation.It allows for comparison between HEIs in relation to the quality of career/employment destinations post-graduation. The data from this is used as a key measure in assessing the performance of HEIs in league tables. More recent initiatives in the UK linking the achievement of such measures to student funding (i.e. the Teaching Excellence Framework, TEF) are designed to further force the hand of University management in delivering employability. It is worth noting however that any data applied for such measurements needs to be placed in context, as data collection methodologies are reviewed to meet the scrutiny of a wider range of users. As such the next data set for DLHE, implemented as the Graduate Outcomes collection will not be published until January 2020 (HESA 2017b). Importantly what remains is that Artess et al.

(2017) suggest that employability has now become one of the top priorities for HEIs.

\section{Defining Employability: Understanding Competencies}

Understanding the employer approach to employability is fundamental to addressing the issue. Professional bodies have a substantial influence over the curriculum in traditional vocational degrees, such as law or nursing, and the importance of the curriculum in defining employability, knowledge acquisition and training for a career is widely accepted. Many other programmes, such as those in Computing, whilst they are vocational are not training individuals for specific jobs, do aim to facilitate the possession of a mix of employability skills and business knowledge desired by employers. However, today's school children will likely go on to graduate from University and in future work in organisations and job roles that don't yet exist. Upheaval and fluidity in the job market mean that employability is increasingly defined by one's possession of, and ability to articulate, a given set of competencies, alongside requisite technical skills (e.g. Independent 2015; Times Higher 2015).

Thefocusoncompetenciesinthejobapplicationprocesshasbecomeeverstronger in the 21st century: students who can demonstrate these competencies have a substantial advantage in seeking graduate jobs and future promotion.

The Higher Education Academy (HEA 2015) identified a composite list of 34 terms associated with graduate attributes, suggesting that employability is difficult to define, and being able todemonstrate competency isalsorather slippery, described as "a personal state that individuals occupy" (Artess et al. 2017, p 10). More usefully, Dubois (1998) defines competencies as those characteristics-knowledge, skills, mind-sets and thought patterns - that, when used whether singularly or in various combinations, result in successful performance. There are numerous lists of the competencies most in demand (Diamond et al. 2011): these typically include teamwork, communication \& networking, leadership, business awareness, initiative, flexibility, enthusiasm, personality and many others. 


\section{The Importance of Articulating Competencies}

Therefore, the challenge in HE is not just to teach these competencies but to help students realise their possession and develop the ability to articulate them. Students, however, may not fully recognise the importance of engaging with employability while studying, beyond managing their part-time work (Tymon 2013; Greenbank 2015). Tomlinson, in his Review of Graduate Employability (2012), suggests that many do not appreciate the competencies sought by employers, nor have the knowledge to articulate these, despite this articulation being the most critical component of a typical recruitment process. He adds that it is not just about individuals possessing certain competencies which enhance their employability, but being able to package this for employers:

Brown and Hesketh's (2004) research has clearly shown that ...for graduates, the challenge is being able to package their employability in the form of a dynamic narrative that captures their wider achievements, and which conveys the appropriate personal and social credentials desired by employers. (Tomlinson, p 420)

Tomlinson et al. (2017) have developed this further arguing the need for HEIs to develop a range of 'capitals' with the student:

Capitals can be understood as key resources, accumulated through graduates' educational, social and initial employment experiences, and which equip them favourably when transitioning to the job market. (Tomlinson, p 17)

Such 'capitals' not only include intellectual capital but social capital as well.

If, as suggested, employability for recruiters rests upon an individual candidate's ability to demonstrate their competencies, this has great significance for HEIs developing employability. The challenge therefore is not whether or not HE should seek to develop competencies, but how and in what ways this could be done, taking into account some students' historical lack of engagement in employability initiatives.

\section{$5 \quad$ How to Deliver Employability?}

All Universities have traditionally encouraged their students to consider their future employment and provided support for this, managed via an extra-curricular Careers Service. Typically, they organise employer visits, recruitment fairs and offer careers information, advice and guidance. However, optional engagement with such activities is not sufficient to reach all students and ensure graduates have appropriate employability knowledge and understanding. Thus, many institutions look to the curriculum to see whether and how they can embed employability. This has been given recent impetus in the UK by the support of the Higher Education Academy (HEA) which published a framework for employability in tertiary education (Cole andTibby2013).TheHEA'sreportonPedagogyforEmployability(Peggetal.2012) 
includes many case studies on embedding employability in the curriculum. None of these however, explicitly link course assessment to the articulation of student competencies in the way described later in this paper.

\section{Should Employability Be Developed Within the Curriculum?}

Cranmer (2006) conducted research amongst a group of UK Universities, looking at different models of delivery, and concluded that there was limited evidence of the development of 'employability skills' through classroom teaching. She argued that resources would be more usefully deployed by HEIs in employment based training, employer involvement in the curriculum and opportunities for experience with employers such as placements/internships. Her conclusions suggested that teaching employability skills was not achievable or (even) desirable. Tymon (2013, p 853), acknowledges the complexity of employability and further questioned whether the development of employability was within the capability of HE institutions:

It is also unclear whether many of these skills and attributes can be developed in practice and, if so, what the role of higher education institutions should be. Putting aside the arguments about whether higher education institutions are able, willing or designed to develop employability, there is evidence to suggest there are alternative options which may be more appropriate.

Tymon (2013, p 853) goes on to declare that with improvement from HEI's:

Skills can be developed and are embedded in the curriculum, but many first and second year students appear to lack engagement with these activities. This must reduce their motivation to learn and inevitably impact on successful development.

Tymon concludes that "development of these [employability skills] is possibly outside the capability and remit of higher education institutions."

\section{$7 \quad$ Making Employability in the Curriculum Work}

There is a lack of evidence of the efficacy of seeking to 'teach' or 'develop' the competencies sought by employers. Such efforts can appear to clash with the priority of the curriculum, rightly focused on the subject content of the degree. Our own initiative arose from reflection on the failure of: a) previous efforts to prescribe a Progress File as part of an earlier Personal Development Planning (PDP) initiative and b) extra-curricular employability initiatives to engage the majority of students. In terms of this study, the demographics of the student population were a key driver behind the embedded nature of the module described below. The University has a relatively high proportion of students from Widening Participation backgrounds, currently standing at $42 \%$ of the population (University of Salford 2017). 
Thispapersuggeststhatwhileitmaynotbepossibletoinstructstudentsinemployabilit $y$, we can guide them to construct their employability on the basis of their prior experience and knowledge. This knowledge comes from their learning both within and outside the curriculum. For this to be effective, students not only need to appreciate the importance of employability in general but, most importantly, they need to cross the threshold between their understanding and that of employers.

\section{$8 \quad$ Threshold Concepts and Employability}

Meyer and Land developed the theory of Threshold Concepts in 2003 following a research project into the characteristics of effective undergraduate education, particularly in the field of economics. Akin to a portal, achieving a threshold opened up a "new and previously inaccessible way of thinking about something ... it represents a transformed way of understanding, or interpreting, or viewing ... without which the learner cannot progress" (Meyer and Land 2003). Subsequent investigation has shown that the central tenet of mastery of a subject via Threshold Concepts could be applied to any subject, demonstrating the broader applicability of Meyer and Land's original findings. In particular, work by Cousin (2010) has demonstrated the significance of Threshold Concepts in developing pedagogy as well as facilitating subject specific knowledge. A good example to illustrate new understanding would be a shift from a student of French to a French speaker (Cousin 2010).

Thisunderstanding,consideredsoimportantbytheirtutors, isbothtransformative and irreversible and is not (we would argue) discipline specific. Threshold Concepts have non-subject specific features in common. Their significance in HE has been explored more fully in a more recent collection of work published in 2016 (Land, Meyer and Flanagan 2016). Flanagan (2017) has summarised the features of Threshold Concepts, in Table 1.

The concept of liminality resulted from additional research by Meyer and Land, published in 2006. Liminality involves the active engagement of the learner, as this threshold is crossed back and forth as the student experiences both positive and unsettling shifts in comprehension. Cousin (2010) compares this idea to the age of adolescence. In learning it can involve a period of understanding and misunderstanding at the same time: the experience can be very emotional. The first experience of a job interview is a good example: the experience can be very emotional involving a combination of understanding and misunderstanding. Effective performance in face to face interviews and other employer engagement (for example assessment centres and online video interviews) require a clear understanding of the employer perspective which, when achieved, is a threshold of employability. Achieving a clear understanding of employability meets the description of a Threshold Concept well.

Burch et al. (2014), in their paper on 'Identifying and overcoming threshold concepts and conceptions', stress the importance and difficulty of changing 
curriculum design and delivery in order to apply the theory. Cousin (2010) argues that a teaching strategy informed by the practical application of Threshold Concepts allows

Table 1 Summary of threshold Concepts. Adapted from Flanagan (2017)

\begin{tabular}{l|l}
\hline Threshold feature & Impact characteristics \\
\hline Transformative & $\begin{array}{l}\text { Once understood, a threshold concept changes the way in which the } \\
\text { student views the discipline }\end{array}$ \\
\hline Troublesome & $\begin{array}{l}\text { Threshold Concepts are likely to be troublesome for the student. } \\
\text { Perkins (1999) has suggested that knowledge can be troublesome } \\
\text { e.g. } \\
\text { when it is counter-intuitive, alien or seemingly incoherent }\end{array}$ \\
\hline Irreversible & $\begin{array}{l}\text { Given their transformative potential, Threshold Concepts are also } \\
\text { likely to be irreversible, i.e. they are difficult to unlearn }\end{array}$ \\
\hline Integrative & $\begin{array}{l}\text { Threshold Concepts, once learned, are likely to bring together } \\
\text { different aspects of the subject that previously did not appear, to the } \\
\text { student, to be related }\end{array}$ \\
\hline Bounded & $\begin{array}{l}\text { A Threshold Concept will probably delineate a particular conceptual } \\
\text { space, serving a specific and limited purpose }\end{array}$ \\
\hline Discursive & $\begin{array}{l}\text { Meye, Land and Davies (2006) suggest that the crossing of a } \\
\text { threshold will incorporate an enhanced and extended use of } \\
\text { language }\end{array}$ \\
\hline Reconstitutive & $\begin{array}{l}\text { Understanding a threshold concept may entail a shift in learner } \\
\text { subjectivity }\end{array}$ \\
\hline Liminality & $\begin{array}{l}\text { Comparing the crossing of the pedagogic threshold to a rite of } \\
\text { passage, involving a potentially messy journey to learning. } \\
\text { Liminality requires active engagement of the learner, as this } \\
\text { threshold is crossed back and forth as the student experiences both } \\
\text { positive and unsettling shifts in comprehension }\end{array}$ \\
\hline
\end{tabular}

academics to steer a path between teaching-centred and student-centred education, making it appealing across all disciplines. In practice this involves a change of focus from the teaching to the learning, with a particular focus on how the student can develop their learning on the basis of their prior experience.

\section{Constructing Employability}

In considering our best approach to guide the students towards the threshold of employability, the solution devised follows a constructivist approach to learning and teaching: our approach can be characterised by a saying attributed to Plutarch: "the mind is not a vessel to be filled, but a fire to be lit". Boud et al. (1985) work on 'Reflection: turning experience into learning' was valuable. This advocates the use of assessment and reflection in motivating learning. Wiggins and McTighe (1998) also argue in their book 'Understanding by Design' for the idea of deciding first upon the outcome required and then designing the assessment accordingly. Boud 
suggests further that the teaching and assessment process needs to enable students to draw on their previous experience and knowledge so that they can 'take some significant responsibility for their own learning over and above responding to instruction' (Boud 1988, p 32). As Villar and Albertin (2010) suggest, students need to become more actively involved and responsible for their education, investing in their own social capital. Providing students with a better understanding of how to do this and opportunities to participate in student-driven activities can develop and/or demonstrate proactive personality in a practical way. These ideas have become well established in the work on Assessment for Learning (Sambell et al. 2013), promoting the idea of using assessment to promote learning rather than measure it. We were also influenced by arguments concerning the significance of authentic assessment, a term popularised in the paper with that title by Fook and Sidu (2010).

\section{The Patchwork Approach to Assessment}

Weadoptedapatchworkapproachtoassessmentasamechanismtoforcetheinvolvement discussedabove.Thisissimilartoanassessmentapproachpossiblemorewidely known as scaffolding. Winter's paper 'Contextualising the Patchwork Text: Addressing problems of coursework assessment in Higher Education' (2003) explains the patchwork approach as follows. Academic staff define the module assessment as a sequence of tasks. The tasks themselves are a process of development designed to guide students to construct their own learning, whilst assimilating new ideas within their existing experience. The tasks are both analytical and experiential.

Winter (2003) likens this to bricolage, where the student is encouraged to improvise for each task according to the social, material and experiential resources they have to hand. In this case students are given quick feedback, and social feedback amongst their peers is encouraged.

Students are asked to synthesise the patchwork through self-reflection at the end. In arguing the value of this, Winter (2003) cites Barnett; "Only in that moment of self-reflection can any real state of intellectual freedom be attained ... Only through becoming a continuing 'reflective practitioner' can the student ... gain a measure of personalintegrity."'Thisofferstheopportunity, asMoon(1999)suggests, forengagemen $\mathrm{t}$ in personal or self-development in addition to gaining insights and empowerment. This final review and interpretation thus also holds the possibility of students demonstrating achievement of a threshold of learning about employability. 


\section{Professional Development Module}

We now discuss how this was put into action in a large 20 credit module (one sixth or a year of study) undertaken by 600s year undergraduates on 11 different degree programmes.

Apatchworkofassessment(Winter2003)wasdesignedtoachievestudentenquiry into their own employability; assessments replicated typical recruitment processes. Figure 1 illustrates the assessment tasks of the module which closely follow pro-

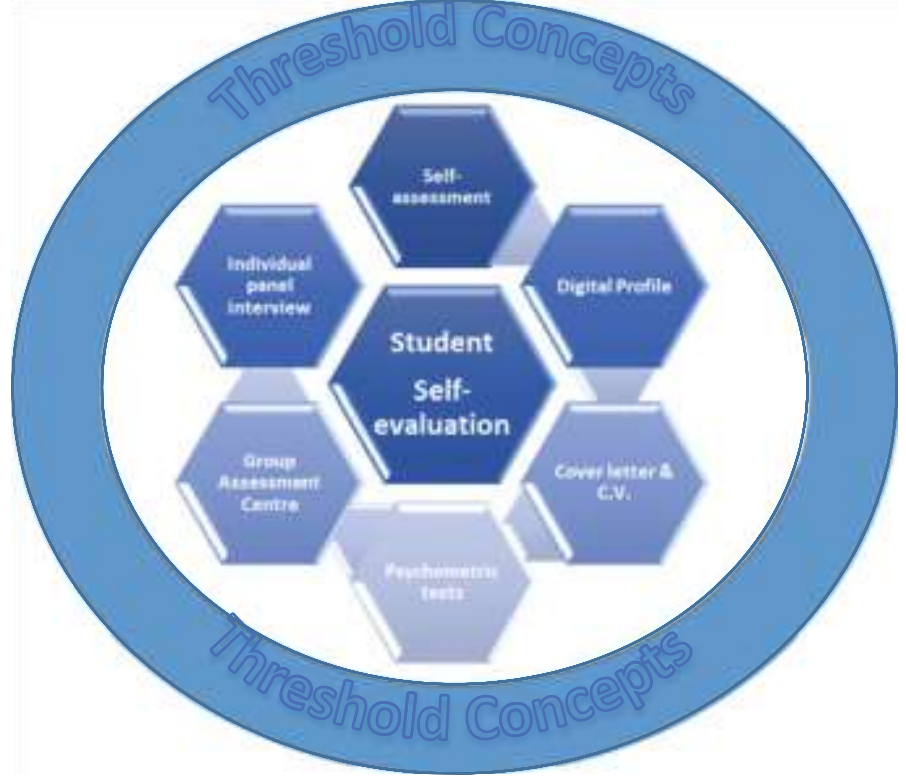

Fig. 1 Professional development patchwork assessment

cesses used by employers in an application process. Academic and careers staff together with employers were involved at every stage-significant evidence is available of the benefits of such partnerships (e.g. O'Leary 2017).

These were initiated by an 'as advertised' job description for which students were set a mixture of tasks, commencing with a self-evaluation presentation to their class. They had to judge their stronger and weaker competencies in relation to the job description, drawing upon a wide range of experiences. They were required to give evidence of their strengths using the Situation, Task, Action, Result (STAR) approach, and an action plan to address areas of improvement. Individual feedback was given and (where necessary) support provided.

Students then created a digital profile using LinkedIn. Unlike other forms of social media, the focus here is upon a professional outlook that illustrates the students' current and future employability, highlighting their skills, experience, extra-curricular activity, as well as a summary of their education. 
Students then submitted a CV and covering letter for the job description provided. Evaluation of this work focussed on the quality and relevance of the application to the criteria specified, rather than the calibre of the student achievement.

All students were required to complete a series of industry standard Psychometric tests. These tests were treated as a learning opportunity to be reflected upon in the final assessment.

Students from many degree programmes were randomly mixed for an assessment centrewhichwasconductedtogetherwithacompanypartner,aimingtobeasauthentic as possible, simulating standard practice in recruitment as used by approximately $90 \%$ of medium to large employers (AGR 2016). Each student was allocated to a group to tackle a business problem followed by a team presentation. The following competencies: leadership, teamwork and communication were assessed.

By once again using the 'as advertised' relevant job description provided, each studentundertookapanelinterview.Thepreparationofrelevantanswersandpositive engagement was key for this element. The process was conducted as realistically as possible with appearance, punctuality and body language forming part of the assessment criteria.

At the end students were required to synthesise and reflect upon their experience and discuss how they would continue to develop their employability and articulate their competencies. The potential to reach the Threshold Concepts for employability permeated the whole development process. Importantly students were asked to reflect not upon the module delivery but rather their own experience of professional development. This could be a critical incident, or perhaps consequence of their performance, that they considered influential to their future development.

This sequence is illustrated in Fig. 1, commencing with the self- assessment, moving clockwise around the hexagon to the interview and then concluding with the student self-evaluation:

Every part of the assessment followed the cycle:

(1) Introduction in lectures by academic staff and explanation by employers and other visitors of the thresholds they expected,

(2) Seminar with opportunity for exercises and detailed explanation, plus questions and answers and feedback on draft work,

(3) Submission of assessment,

(4) Quick feedback online with opportunity for personal feedback in the following seminar or by appointment, allowing for development between tasks,

(5) Finalsummativefeedbackfollowingthefinalwrittenself-reflectionsubmission.

The delivery was resource intensive. Sixty staff, employers and postgraduate students were involved in delivering and assessing the module involving many issues of co-ordination, equity and moderation. Substantial deployment of technology in the assessment process (for example in psychometric testing), numerous different opinions, different cultural backgrounds, and many other 'business as usual' issues created significant complexity. 


\section{Presentation of Data}

The data presented in this paper is drawn verbatim from reflective statements submitted by students undertaking the Professional Development module. It is presented anonymously with their permission. The reflective statements used formed the final element of the patchwork assessment developed for this programme of study (see Fig. 1). In this final element, students are encouraged and required to examine both positive and negative aspects of their professional development and are assessed upon quality of reflection rather than specific performance outcomes.

Wehavedeliberatelyselectedthosestatements(i.e.purposivesampling)thatillustrate the argument of the paper. Threshold features were used as a framework for qualitatively analysing this data, taking a discourse analysis approach (Alvesson and Karreman 2000). It should be pointed out at this stage that a significant minority of students did not consider employability to be a subject worthy of time in the curriculum: these views are not used in the following section. The sample reported upon in this paper has not been broken down by specific degree programme or any other demographic parameter. In combination we suggest that the comments used demonstrate the attainment of intellectual freedom referred to by Barnett cited in Winter (2003) above. The selected quotes are intended to illustrate student insights that suggest the development of an appreciation of employability based upon threshold and constructivist concepts. They are presented as distinct sections but the content is all inter-related:

1. A number of students discussed how the module helped them come to understand the processes of employment:

"During the study of professional development module, I realised the importance of employability skills. I came to know that set of qualities, skills and knowledge that all newly graduates should obtain to ensure they have the skills of being persuasive in the workplace for their own benefit and their employers." (S1)

"From this module, I have found that I have developed my key employability skills a great deal and now feel I would have a lot more confidence when applying for a job role. I have a greater understanding of what employers are looking for in an ideal candidate ... I have learnt that whilst it is important to possess skills such as teamwork, commercial awareness and leadership skills.., it all depends on how you can demonstrate them to the employer by using key experiences and situations to evidence them." (S2)

Both Student 1 and 2 make the point, also raised by others below, that first they needed to understand what was required, and then demonstrate their attainment of this. For some students, including S2, it was patchwork of the module assessment that gave her confidence.

2. Students discussed from their learning that despite initial misgivings, employability was a process of development: 
"AtthebeginningIwasveryapprehensiveaboutitworkingasitisjustaUniversity module. However, from completing it I can say that I have improved in all aspects especially compared to the weaknesses I pointed out I had during the personal skills assessment at the beginning of the module." (S3)

"My journey through Professional Development has been an enlightening and welcome experience. My understanding of self-employability has had a boost and I now feel more confident with the knowledge of what makes me employable such as knowing that being able to demonstrate a skill is just as important as possessing it." (S4)

"By taking this module my employability skills have improved drastically... When I started this module in January I had been rejected by five different companies that I had applied for a placement with. Towards the end I had two placement offers... My employability has increased ... and my confidence has grown. By using Gibbs reflective model (1988) "to promote self-improvement and to link practice to theory." I am able to improve my employability even further." (S5)

It is interesting to see how many students refer to the development of their confidence, a theme discussed further below. What can also be seen is a level of commitment to the task and perseverance as the patchwork assessment progresses and that the relationship between the different recruitment processes was being understood.

3. As with Student 4 above, others discussed the importance of reflection and selfevaluation in the employability journey:

"I have learned from this module that regular self-evaluation is essential, that employability is vital to develop continuously, and that seeking and recording experiences that will enhance employability will enable me not to just have a career for life but be employable for life." (S6)

4. Although students didn't use the term 'threshold' the quotes below suggest that this is indeed what some students reached.

"At the beginning of this module, I was terrible at reflective thinking and writing and didn't see the point in it. Then I began to understand the importance of reflection on everything I do within my life. It made me begin to think about why reflection was important and how it linked with my personal employability. It is important, within an ever changing world, to conduct regular reflections in both thought and in writing, to enable us to be the best version of ourselves that we can be." (S7)

"Looking back at the whole experience of the professional development module, I have realised that the subject is a life changing experience. The module has made me become a better person with a strong persona... Although things were hard at first, it got better with time. This module obviously gave me confidence... I believe after accomplishing this Professional Development module I am now able to manage myself as a professional. I have identified areas that need to be developed and I have already started building on them."(S8) 
5. As can be seen throughout the feedback, gaining confidence was the single most important achievement for many students. This in turn led to a development of their employability and realisation of a threshold:

"The module has helped me transition from an introvert to an extrovert in the working environment by developing my employability skills. I feel that everything I have learnt and developed throughout this module I can develop it by putting it into context when I am on my placement year and further down the line in my working career. From this moment on it is down to me as an individual to develop on the skills I have gained." (S9)

"When I originally learnt the details of the course I was incredibly nervous as I never identified myself as a person who excelled in areas such as group and face to face interviews... However, having reviewed feedback from each assessed piece of work I have completed I realise my worries were without basis. ... This allowed me to identify my main weakness; and it wasn't my time management, my level of business awareness or my Microsoft skills; it was in fact my level of self-confidence. This module has enabled me to build confidence and has allowed me to demonstrate to myself that I can excel in a recruitment process... It has helped me grow in terms of my skills but also as a person and I believe my future employment prospects are improved thanks to the strengths and weaknesses I have identified and built upon." (S10)

"Before starting this module I had low self-confidence and underestimated myself...Overall my feelings at the beginning of this module were negative, however after completing assessments, attending lectures and doing my own research I have learnt a lot about myself in relation to employment. Through feedback and self-evaluation I have determined my strengths [and] this module has helped me develop along with weaknesses which I could improve. As a whole I have achieved well throughout the module which has helped build my selfconfidence." (S11)

"I had not given any thought to the expectations that employers will have from me and was focussed on attaining a good degree. This module has been an enlightening experience to my professional character... The self-reflection I have continuously made in this module has made me realise where my strengths and weaknesses lie." (S12). Whilst quantitative analysis of this module has not been conducted it is probably relevant that in the two years for which destination data is available for students who have undertaken this module, i.e. 2015-16 and 2016-17, there has been a $4 \%$ increase from $2014-15$ in the proportion of graduates reporting themselves in work or further study (increase from 84 to $88 \%$ ). In the absence of further research it isn't possible to claim an association with the module. 


\section{Discussion}

\subsection{Constructing Employability}

The evidence provided by these reflective statements illustrates how the module experience helped students actively construct their employability rather than passively learning about careers. Authentic assessment (Fook and Sidu 2010) was used as an opportunity for learning (Sambell et al. 2013) rather than a simple measure. The Patchwork of assessment, linked to expert advice, feedback and reflection allowed students to build upon the development of competencies. This accords with Perkins (1999, p 8) characterisation of constructivism as an energising process of discovery, one that yields deeper understanding. In attempting to capture the form of active learning described by Perkins, the teaching and learning activities sought to allow students to discover or re-discover principles that fostered understanding with practical results. This is illustrated by comments from $\mathrm{S} 4$ who discusses using reflection for self-improvement, and consequently changing from receiving repeated employer rejections to securing new job offers.

It can also been seen that students (S5 and S11 for example) were learning from employer rejection and assessment feedback, experiencing phases of liminality within the process. By continually engaging in various activities, such as job applications and CV improvement, students as learners entered this liminal space, engaging with the mastery of employability (Meyer et al. 2006).

\subsection{Achieving a Threshold}

The reflective statements illustrate the transformative and irreversible aspects of achieving a threshold of understanding of employability. Understanding why an employer requires a combination of competencies is integrative, and can be morale boosting since the threshold of employability is bounded. For example, the employer may not expect detailed technical expertise from an employee but they may require someone with enthusiasm to learn and an appreciation of their own employability. Student statements highlight the transformation, with S4, S5, and in particular S10 stating their change in attitude towards the module, its teaching and their personal learning. The statements also demonstrate liminality aspects relative to attaining thresholds. The process of understanding is not without difficulty for learners: comments such as feeling "nervous" (S11), having "negative feelings" (S12) or "insecurities" (S13) were common and illustrate the disorientation typical of a state of liminality as discussed by Meyer et al. (2006). Students alternated between embracing and rejecting the module, between anxiety and confidence. Because liminality indicates a period of oscillation, by definition some students will not have realised the threshold of understanding of employability until later in their learning journey. For students, this new understanding can be troublesome in a very 
specific way. For many employers, demonstration of competencies is valued just as highly as qualifications. Some major employers have explicitly said that qualifications are not their primary recruitment metric (Times Higher 2015); rather evidence of employability is of greater significance. Most students have been brought up to believe that the fundamental purpose of their participation in education is the achievement of the highest marks possible. As the final student (S13) says above "my focus was on attaining a good degree", but as S2 comments; "I have a greater understanding of what employers are looking for in an ideal candidate". Empathising with the employer perspective and achieving the threshold of employability involves assimilating this troublesome knowledge and this is an essential part of self-realisation and transformation.

\subsection{The Importance of Confidence}

The student feedback also demonstrates that a constructivist approach can foster confidence, which is an essential ingredient in achieving the threshold of employability. Other researchers have also noted the significance of confidence in the achievement of a Threshold (e.g. White et al. and also Berg et al, cited in Land, Meyer and Flanagan 2016). The module helped students understand the perspectives and

requirementsofemployers, understandtheirowndevelopment, appreciatetheimportanc e of reflection, gain confidence and thus realise a threshold. As S8 comments, "I have realised that the subject is a life changing experience. The module has made me become a better person with a strong persona... This module obviously gave me confidence". Hawkins and Edwards (2013) discuss the 'monsters of doubt' that students experience when learning about leadership. These same monsters equally apply to employability. A key moment is when students understand clearly the competencies employers seek, why they are sought, and how to articulate them. This threshold may be reached after numerous job applications, assessment centres, interviews, or through real experience in employment. Discovering how to effectively articulate their competencies can be a lightbulb moment for students.

Many of the reflective statements submitted for assessment across the cohort include comments relating to increasing confidence. Once students grasp the linkage between their own skills and those required by employers, i.e. an integrative concept, they are creating knowledge for and of themselves that can be applied across

the

variousaspectsofemployability.Theconfidenceandperseverancewesawfrommany ofthestudentswasalsoanimportantaspectofmaintainingengagementthatCranmer (2006) and Tymon (2013) suggested was lacking in other initiatives concerned with the development of employability in the curriculum. This is particularly important as itfeedsintothebenefitsofanactiveandconstructivistlearningapproachasdiscussed in our research.

Contrary to the work of Tymon (2013) and others, this paper suggests that HE can and should help guide students toward this self-realisation through the curriculum. This is demonstrated via a collaborative approach. To accomplish this 
does require a re-organisation of the curriculum (as suggested by Burch et al. 2014), starting with a focus on the final aim (the articulation of competencies), and working backwards through design of multiple assessments to achieve this aim. Substantial teamwork - including the involvement of employers-was essential in guiding students to this final aim or threshold. This approach succeeded in engaging the great majority of students. It also enabled a mind-set change for some of the significant minority to become engaged, to realise the importance of employability and how it applies to them. Overall it was thus much more effective than relying solely on 'traditional' extra-curricular support.

\section{Conclusions}

Demonstrating employability has become a central component of UK government policyinregards toHigher Education, andHEIshave madeemployability akeycomponent of their mission. However, the ability to articulate employability skills, more commonly now known by employers as competencies, is not equally distributed and is related to the social capital that is held (Villar and Albertin 2010). Students have or can nurture competencies, but may not appreciate how to do this or how to express the same. This is where Higher Education can provide interventions and, to some degree, light the fire. If well designed, HE can help students construct their own employability, and thus enhance their experience of education more broadly. This paper has argued for the importance of embedding employability in the curriculum, guiding students to realise the threshold of employer expectations, and as a consequence construct their employability in more effective ways. The use of assessment and specifically, a Patchwork Approach (Winter 2003), is valuable in this process.

The paper explains the design and implementation of a module that has allowed students to recognise their competencies so widely cited as requirements by employers (Tomlinson 2012; Tymon 2013). This module has now been undertaken over a period of five years. Evidence of the efficacy of this approach is provided in excerpts from student reflections: further longitudinal and quantitative research would

necessarytogaugethelongtermimpact.Thesinglemostimportantlessontocomeoutof the feedback from students involved is that confidence is fundamental to expressing competencies and demonstrating employability. Confidence is key to achieving the ThresholdofEmployability. Whilstthesignificanceofsocialcapitaltoemployability is widely accepted, we were not aware of the importance of emotional (Cousin 2006) and psychological capital (Luthens 2007) for students in navigating the liminal space between HE and employability. These issues are clearly presented by Rattray (2016) opening up a whole body of work in Positive Psychology (e.g. Ivtzan and Lomas 2016) which we haven't addressed in the paper. 
Valuable further research can be conducted on employability initiatives in HE which take as a starting point the development of student confidence built within the curriculum.

\section{References}

AGR (2016) The Association of graduate recruiters annual survey at: http://justoncampus.co.uk/w p-content/uploads/2016-AGR-Annual-Survey-2.pdf. Accessed 20 June 2018

Alvesson M, Kärreman D (2000) Varieties of discourse: on the study of organizations through discourse analysis. Human Relat 53(19):1125-1149

Archer W, Davison J (2008) Graduate employability: the view of employers. Council for Industry and Higher Education, London

Artess J, Mellors-Bourne R, Hooley T (2017) Employability : a review of the literature 2012-2016. Available at https://www.heacademy.ac.uk/knowledge-hub/employability-review-literature201

2-2016. Accessed 20 June 2018

Barr N (2014) Shaping higher education: 50 years after Robbins. In: Barr N (ed). LSE, London

BIS(2016a)Graduatemarketlabourstatistics2015.DepartmentforBusiness,InnovationandSkills, London

BIS (2016b) Success as a knowledge economy: teaching excellence, social mobility and student choice. Department for Business, Innovation and Skills, London

Boud D, Keogh R, Walker D (1985) Reflection: turning experience into learning. Routledge Farmer, Oxon

Boud D (1988) Developing student autonomy in learning, 2nd edn. Kogan Page, London

Brown P, Hesketh AJ (2004) The mismanagement of talent: employability and jobs in the knowledge-based economy. Oxford University Press, Oxford

Burch G, Burch J, Bradley T, Heller N (2014) Identifying and overcoming threshold concepts and conceptions. J Manage Educ 39(4):476-496

CBI (2015) Inspiring growth CBI/Pearson Education and skills survey 2015. London, UK

CIPD (2014) Industrial strategy and the future of skills policy. CIPD, London, UK

CIPD (2015) Policy report: over-qualification and skills mismatch in the graduate labour market. CIPD, London, UK

Cole D, Tibby M (2013) Defining and developing your approach to employability: a framework for higher education institutions Higher. Education Academy, available at: https://www.heacademy. ac.uk/system/files/resources/employability_framework.pdf. Accessed 20 June 2018

Cousin G (2006) Threshold concepts, troublesome knowledge and emotional capital: an exploration into learning about others. In: Meyer JHF, Land R (eds) Overcoming barriers to Student understanding: threshold concepts and troublesome knowledge. Routledge, London and New York

Cousin G (2010) Neither teacher-centred nor student-centred: threshold concepts and research partnerships. J Learn Dev Higher Educ (2)

Cranmer S (2006) Enhancing graduate employability: best intentions and mixed outcomes. Stud High Educ 31(2):169-184

Diamond A, et al (2011) Global Graduates into Global Leaders. AGCAS and others

Dubois D (ed) (1998) The competency casebook. International Society for Performance Improvement, Amherst, MA, HRD, \& Silver Spring MD

FlanaganM(2017)Thresholdconcepts:undergraduateteaching,postgraduatetraining,professional development and school education. Available at: https://www.ee.ucl.ac.uk/ mflanaga/threshold s.html accessed 20 June 18 
Fook CY, Sidu GK (2010) Authentic assessment and pedagogic strategies in higher education. J Soc Sci 6(2):153-161

Greenbank P (2015) Still focusing on the "essential 2: 1": exploring student attitudes to extracurricular activities. Educ+Training 57(2):184-203

Guardian (2016) Editorial: The guardian view on graduates and employment: degrees but not destinations. https://www.theguardian.com/commentisfree/2016/may/03/the-guardian-viewongraduates-and-employment-degrees-but-not-destinations. Accessed 30 Mar 2017 and 20 June 2018

Hawkins B, Edwards G (2013) Managing the monsters of doubt: liminality, threshold concepts and leadership learning. Manage Learn

HEA (2015) https://www.heacademy.ac.uk/knowledge-hub/graduate-attributes-framework. Accessed 29 Mar 2018 and 20 June 2018

HEFCE (2017) Computer science employability and accreditation. Review led by Nigel Shadbolt http://www.hefce.ac.uk/skills/gradstemreview/csreview/. Accessed 21 May 2018

HESA (2017a) Higher education student enrolments and qualifications obtained at higher education providers in the United Kingdom 2015/16. https://www.hesa.ac.uk/news/12-012017/sfr242-st udent-enrolments-and-qualifications. Accessed 15 Dec 2017

HESA (2017b) NewDLHE: destinations and outcomes review. Accessed 27 June 2018

Independent (2015) Leading employers prefer value work experience among graduates over grades. http://www.independent.co.uk/news/education/education-news/leading-employersprefer-wor k-experience-over-grades-says-new-research-10286829.html. Accessed 31 May 2015

Ivtzan I, Lomas T (2016) Mindfulness in positive psychology. Routledge

Land R, Meyer JHF, Flanagan MT (2016) Threshold concepts in practice. Sense Publishers, Rotterdam, Taipei \& Boston

LuthansF,YoussefCM,AvolioBJ(2007)PsychologicalCapital.OxfordUniversityPress,NewYork

Matthews S (2017) Tech City Talent and Computer Science Graduate Employability: an independent learning review for the Tech Partnership and the JPMorgan's Chase Foundation. https:// www.thetechpartnership.com/globalassets/pdfs/research2017/techcitytalentandcomputerscienc egraduateemployability_report_may2017.pdf. Accessed 24 Apr 2018

Meyer JHF, Land R (2003) Threshold concepts and troublesome knowledge 1-Linkages to ways of thinking and practising in improving student learning-Ten years on. In: Rust $\mathrm{C}$ (ed). OCSLD, Oxford

Meyer JHF, Land R, Davies P (2006) Implications of threshold concepts for course design and evaluation. In Meyer JHF, Land R (eds) Overcoming barriers to student understanding: threshold concepts and troublesome knowledge. Routledge, London and New York

Moon J (1999) Reflection in learning and professional development: theory and practice. Routledge-Falmer, Abingdon

NCIHE (1997) Higher education in the learning society http://www.educationengland.org.uk/doc uments/dearing1997/dearing1997.html. Accessed 20 June 2018

O'Leary S (2017) Enhancing graduate attributes and employability through initiative with external partners. Pract Evid Sch Teach Learn High Educ 12(3)

Pegg A, Waldock J, Hendy-Isaac S, Lawton R (2012) Pedagogy for employability. Available at https://www.heacademy.ac.uk/system/files/pedagogy_for_employability_update_2012.pdf

Perkins D (1999) The many faces of constructivism. Educ Leadersh 57(3)

Rattray J (2016) Affective dimensions of liminality. In: Land R, Meyer J, Flanagan M (eds) Threshold concepts in practice. In: Peters MA (Series Editor) Educational futures: rethinking theory and practice, vol 68. Sense Publishers, Rotterdam/Boston/Taipei

Sambell K, McDowell K, Montgomery C (2013) Assessment for Learning in Higher Education. Routledge, London

Times Higher (2015) Ernst and Young drops degree classification threshold for graduate recruitment. Available at https://www.timeshighereducation.co.uk/news/ernst-and-youngdrops-degre e-classification-threshold-graduate-recruitment. Accessed 20 June 18 
Tomlinson M (2012) Graduate employability: a review of conceptual and empirical themes. High Educ Policy 25:407-431

Tomlinson M, McCafferty H, Fuge H, Wood K (2017) Resources and readiness: the graduate capital perspective as a new approach to graduate employability. J Natl Inst Career Educ Counselling 38(1):28-35

Tymon A (2013) The student perspective on employability. Stud Higher Educ 38(6):841-856

University of Salford (2017) TEF 2 provider submission. University of Salford

Villar E, Albertin P (2010) 'It is who knows you'. The positions of university students regarding intentional investments in social capital. Stud High Educ 35(2):137-154

Wiggins G, McTighe J (1998) Understanding by design. Association for Supervision and Curriculum Development, Alexandria, VA

Winter R (2003) Contextualizing the patchwork text: addressing problems of coursework assessment in higher education. Innovations Educ Teach Int 40(2):112-122

Woods A, Dennis C (2009) What do UK small and medium sized enterprises think about employing graduates? J Small Bus Enterp Dev 16(4):642-659 